\title{
Correction to: Alleviation of tetrabromobisphenol A toxicity in soybean seedlings by Rhodopseudomonas palustris RP11
}

\author{
Honglian $\mathrm{Ge}^{1} \cdot$ Zhonghua Liu $^{1}$
}

Published online: 3 February 2020

c) Springer-Verlag GmbH Germany, part of Springer Nature 2020

\section{Correction to: Archives of Microbiology} https://doi.org/10.1007/s00203-019-01797-8

The original article has published with the incorrect article title. The correct title is "Alleviation of tetrabromobisphenol A toxicity in soybean seedlings by Rhodopseudomonas palustris RP11"

Publisher's Note Springer Nature remains neutral with regard to jurisdictional claims in published maps and institutional affiliations.

The original article can be found online at https://doi.org/10.1007/ s00203-019-01797-8.

Honglian Ge

gehonglian2003@126.com

1 College of Life Science and Agronomy, Zhoukou Normal University, Zhoukou 466001, China 